\title{
Educaçáo inclusiva e prática pedagógica: um estudo de caso com professores de alunos com deficiência mental no ensino fundamental
}

\author{
Elaine Cristina Batista Borges de Oliveira*
}

\begin{abstract}
Resumo
A presente pesquisa analisou os caminhos utilizados por professores do ciclo II do ensino fundamental, de uma unidade escolar da região de Marília, no trato com a inclusão dos alunos com deficiência mental. Para isso, investigou a prática pedagógica e os métodos utilizados para amparar, adaptar e incluir os alunos com problemas cognitivos nos processos de desenvolvimento e de aprendizagem em salas regulares do ensino fundamental. Demonstrouse, assim, a condição do aluno incluído, em particular, dos alunos com deficiência mental, com abordagens das principais leis e teorias sobre o tema, em relaçáo às ações pedagógicas existentes nos discursos dos professores para uma prática educacional não segregadora. Entre as conclusões da pesquisa aparece a constatação da existência de um distanciamento entre a teoria e a prática pedagógica dos docentes quanto à açáo inclusiva, bem como o desinteresse em efetivar açóes pedagógicas para uma prática em favor dos alunos com necessidades educativas especiais.
\end{abstract}

Palavras-chave: inclusão escolar, necessidades educacionais especiais, prática pedagógica.

Inclusive education and pedagogical practice: a case study involving teachers of students with mental disabilities in elementary education

\begin{abstract}
This research examined how teachers of the second cycle of primary education, in a school in the region of Marília dealt with the inclusion of students with mental disabilities. To do so, the pedagogical practices and methods used to support, adapt and include students with cognitive problems in the processes of development and learning in regular classrooms at elementary level were analyzed. It demonstrated the conditions of included students, and in particular, those with mental disabilities and addresses the principal laws and theories on the subject in relation to pedagogical practices present in teachers' discourses in order to offer non-segregating educational practice. One of the conclusions of the research is that there is a gap between the theory and pedagogical practice of teachers in terms of inclusive action and reluctance/unwillingness to use pedagogical actions which would lead to a practice which is advantageous for students with special educational needs.
\end{abstract}

Keywords: school inclusion, special educational needs, pedagogical practice.

* Pedagoga, mestranda do Programa de Pós-Graduação em Educação da Faculdade de Filosofia e Ciências - Universidade Estadual Paulista “Júlio de Mesquita Filho", Campus de Marília, 2012. E-mail: ecbbo@yahoo.com.br 


\section{Introdução}

O exame histórico das discussões sobre a Educação Especial demonstra que a trajetória dos alunos com necessidades educativas especiais tem sido acompanhada por muita resistência e dificuldades na implementação de uma inclusão plena e de qualidade. Todavia, nota-se que as preocupações com as políticas educacionais de inclusão da pessoa deficiente vêm aumentando consideravelmente no Brasil, principalmente após a década de 1990, com o surgimento de importantes documentos e leis específicas sobre esse campo de discussão.

Entre esses documentos e leis que trouxeram avanços às políticas educacionais de inclusão e inserção das pessoas com necessidades educativas especiais estão a Declaração Mundial de Educação para Todos (BRASIL, 1990), o Plano Decenal de Educação para Todos (BRASIL, 1993), a Declaração de Salamanca (BRASIL, 1994), a Lei de Diretrizes e Bases da Educação Nacional (BRASIL, 1996), entre outros documentos.

Tais documentos e leis ajudaram a diminuir sensivelmente os discursos e práticas segregacionistas, estigmatizantes e preconceituosas perpetuadas em outras épocas no contexto escolar, contribuindo para a construção de novas práticas nas açóes inclusivas entre professores e alunos com necessidades especiais, nestes últimos tempos. Apesar desses avanços, observa-se, ainda, a inoportuna presença no ambiente escolar de uma estrutura e prática docente excludentes, contrariando os progressos conquistados até o momento. Nesse sentido, Mazzotta (1987) aborda a questáo enfatizando a necessidade de uma integração total e de qualidade:

Essa integraçáo do aluno deficiente mental na escola comum, todavia, não pode ser confundida com a subescolarização. Ela deve significar a busca concreta de uma adequação do meio escolar comum aos objetivos educacionais das crianças deficientes mentais. (MAZZOTTA, 1987)

A presente pesquisa teve, então, o objetivo de refletir sobre os discursos dos professores do ensino fundamental e sobre a inclusão dos alunos com deficiência mental (DM) na sala regular de ensino. Para tanto, a partir de uma pesquisa de campo, investigou os discursos de professores do ciclo II, de uma escola da rede estadual da regiáo de Marília-SP, por entender que ouvir a voz dos principais agentes que lidam diretamente com a inclusão no ambiente escolar - os professores - era essencial para compreender suas dú- 
vidas, dificuldades, observaçôes e principais necessidades, enquanto professores convocados a serem instrumentos principais da inserção do aluno com deficiência no ambiente escolar.

Refletindo sobre a conceituação de deficiência mental, antes de aprofundar nas discussōes metodológicas, resultados e discussóes da pesquisa, indica-se que há uma diversidade de conceitos e definiçóes para deficiência mental, uma vez que se apresentam questóes complexas e plurais em torno de suas causas. Podem-se encontrar motivos variados para explicar as dificuldades intelectuais.

A Declaração dos Direitos das Pessoas Deficientes (BRASIL, 1975), aprovada pela assembléia geral da ONU, em 9 de dezembro de 1975, indica em seu artigo $1^{\circ}$ que "O termo 'pessoas deficientes' refere-se a qualquer pessoa incapaz de assegurar por si mesma, total ou parcialmente, as necessidades de uma vida individual ou social normal, em decorrência de uma deficiência, congênita ou não, em suas capacidades físicas ou mentais" (BRASIL, 2011). O Manual de Diagnóstico e Estatística das Perturbaçóes Mentais/ DSM-IV (BRASIL, 1995) descreveu mais especificamente os diversos tipos de perturbaçôes mentais. É um manual para profissionais da área da saúde mental que lista diferentes categorias de transtornos mentais e critérios para diagnosticá-los, de acordo com a Associação Americana de Psiquiatria (American Psychiatric Association (APA), principal organização profissional de psiquiatras dos Estados Unidos), incluindo formas de tratamento e outras questóes específicas. É instrumento de trabalho de referência para os diversos profissionais da saúde mental. O Manual afirma:

A característica essencial do Retardo Mental é quando a pessoa tem um "funcionamento intelectual" significativamente inferior à média, acompanhado de limitaçóes significativas no funcionamento adaptativo em pelo menos duas das seguintes áreas de habilidades: comunicação, autocuidados, vida doméstica, habilidades sociais, relacionamento interpessoal, uso de recursos comunitários, autossuficiência, habilidades acadêmicas, trabalho, lazer, saúde e segurança. (BRASIL, 1995)

A Classificação Internacional de Doenças e Problemas Relacionados à Saúde/CID-10 (Brasil, 1993), documento publicado pela Organização Mundial da Saúde (organismo internacional de saúde pública, de alcance mundial), é outro guia de referência em termos de pesquisa em saúde mental. Propóe uma classificação em relação à gravidade da deficiência mental e, também, a outros problemas referentes à saúde. Publicou um 
documento classificando a deficiência mental em quatro níveis: profundo, grave, moderado e leve.

Segundo a Organização Mundial da Saúde (1993), no nível profundo classificam-se as pessoas com uma incapacidade total de autonomia. O nível grave considera de forma fundamental a necessidade de estimular a autonomia, a capacidade de comunicação e a aprendizagem. $\mathrm{O}$ nível moderado engloba os alunos com possibilidade de alcançar o grau pré-operativo (pessoas que podem ser capazes de adquirir hábitos de autonomia e realizar certas atitudes bem elaboradas, mesmo que tenham constante necessidade de supervisão). No nível leve se encaixam os alunos perfeitamente educáveis.

De acordo com Pletsch (2010), em diferentes países e no Brasil, a Associação Americana de Retardo Mental (AAMR), adotada pelos órgãos oficiais e pelos estudiosos da área desde a década de 1970, é reconhecida como referência para definir, diagnosticar e classificar a deficiência mental. Segundo a AAMR, a deficiência mental é definida como "um funcionamento intelectual significativamente abaixo da média, originado no período de desenvolvimento, e que é concorrente com os déficits no comportamento adaptativo".

Historicamente, os alunos com deficiência sempre sofreram com o olhar de estigmatização, discriminação e preconceito. Observa-se que havia uma preocupaçáo inicial meramente assistencialista/terapêutica, e apenas posteriormente de integração/inserção quantitativa, sem a devida preocupação com uma inclusão qualitativa.

A escolarizaçáo dos alunos com necessidades educativas especiais, segundo o texto de Kassar (2004), é recomendada no Brasil desde a LDB n. 4.024, de 1961. Porém, surgiu sustentada pelo argumento da necessidade de separação dos alunos "normais" e "anormais", apoiada pela pedagogia científica (pedagogia que fazia uso de conceitos estereotipados de normalidade, anormalidade ou degeneração), para que pudessem ser tratados exatamente de acordo com suas necessidades. Assim, os alunos com necessidades educativas especiais, em sua maioria, eram atendidos na rede privada, onde recebiam atendimento mais específico, ou melhor, mais terapêutico e menos escolar.

No final do século XX, o sistema de ensino no país tornou-se cada vez mais envolvido com as recomendaçóes da educação inclusiva, começando a ganhar novos adeptos, através de documentos como a Declaração Mundial 
de Educação para Todos (1990), aprovada pela ONU, o Plano Decenal de Educação para Todos (1993), entre outros. Em seguida, a Unesco registrou, na Declaração de Salamanca (1994), o conceito de "inclusão" no campo da educação comum, principalmente no sentido de que todas as escolas estivessem preparadas para receber todos os alunos, inclusive os que apresentassem algum tipo de deficiência; além disso, que os professores tivessem formação adequada para receber esses alunos.

A Declaração de Salamanca salienta, em determinado momento do documento, que é recomendado aos países que "adotem o princípio de educação inclusiva em forma de lei ou de política, matriculando todas as crianças em escolas regulares". Ressalvando a estes países que "a menos que existam fortes razóes para agir de outra forma, que ainda garantam no contexto de uma mudança sistêmica programas de treinamento de professores, tanto em serviço como durante a formação, incluam a provisão de educação especial dentro das escolas inclusivas" (BRASIL, 1994).

A Lei de Diretrizes e Bases da Educação Nacional garante, em seu artigo $2^{\circ}$, o atendimento aos educandos com necessidades educativas especiais em todo o sistema regular de ensino, promovendo as condiçóes necessárias para uma educação de qualidade para todos (BRASIL, 1996).

Sassaki (1997) afirmou que precisávamos o quanto antes trabalhar por uma inclusão social e, para isso, deveríamos contar com uma inclusão escolar com qualidade de ensino, buscando desenvolver açóes compatíveis com as leis que favorecem a diversidade e apontam caminhos para uma inclusão concreta e eficaz. Afirmou: "Quanto mais sistemas comuns da sociedade adotarem a inclusão, mais cedo se completará a construção de uma verdadeira sociedade para todos: a sociedade inclusiva."

Carvalho (2004) denunciou que a educação inclusiva, em sua maioria, não ocorria como deveria, de forma efetiva, mas muitas vezes era mascarada por uma aceitação de aparência, apenas para demonstrar aceitação da política inclusiva e de uma escola favorável à diversidade.

É importante ressaltar que a finalidade da educação escolar como ação transformadora, coerente com o objetivo de promoção humana, deveria estar vinculada com atividades teórico-práticas adequadas às necessidades de todos:

A proposta é, portanto, a de ressignificar a prática pedagógica nas classes comuns, tendo em conta: a sala de aula (aspecto físico/arquitetônico, mobiliário, o clima afetivo etc.); a ação didático-pedagógica (planeja- 
mento dos trabalhos em equipe, atividades curriculares "fora da escola"); revisão da metodologia didática, desenvolvendo-se mais trabalhos em grupo. (CARVALHO, 2004)

Defender a inclusão social e educacional da pessoa com deficiência mental, com base nos princípios éticos e democráticos que fundamentam a legislação brasileira e internacional em relação ao ambiente escolar, inclui a responsabilidade de toda uma equipe escolar e náo somente do professor da sala de aula, e, também, reflexóes que envolvam todos que participam direta e indiretamente da ação educativa; conforme Carvalho (2004), outra vez, relata: "Mas é injusto e perverso localizar as necessárias transformaçóes só e apenas nas atitudes dos professores e em sua prática pedagógica."

O documento do MEC - "Saberes e Práticas da Inclusão" (BRASIL, 2006) - atenta para as Linhas de Ação sobre Necessidades Educacionais Especiais com base na experiência dos países participantes e também nas resoluçóes, recomendaçóes e publicaçóes do sistema das Naçóes Unidas e de outras organizaçóes intergovernamentais. No artigo 41, salienta que todos os programas de formação inicial deverão oferecer orientaçôes e práticas sobre a deficiência que possibilitem ao professor saber com quais suportes e serviços de apoio ele poderá contar para aperfeiçoar sua prática inclusiva de forma autônoma, aplicada, instrutiva e colaborativa, na relaçáo com os diversos especialistas e pais envolvidos com a inclusão.

A partir do momento em que se abrirem os espaços para discussóes da melhor forma de trabalhar a inclusão, com identificação dos sucessos e insucessos e avaliação da capacitação dos professores - que precisam repensar a sua forma de atuar e lidar com os alunos na diversidade -, certamente contribuiremos para a constituição de salas de aula adequadas para receber as pessoas com necessidades educativas especiais e para a construção de um novo paradigma de escola inclusiva.

Concluindo, espera-se que o presente trabalho possa contribuir para apontar caminhos que facilitem as açóes pedagógicas inclusivas no ensino fundamental, ciclo II, em particular, junto aos alunos com Deficiência Mental.

\section{Metodologia}

A presente pesquisa, de natureza aplicada, com abordagem qualitativa e caráter exploratório, buscou investigar os discursos de professores do 
ensino fundamental, ciclo II, da rede estadual de educação da região de Marília-SP, com vistas a compreender como esses docentes lidam com a questáo da inclusão, especialmente de alunos com deficiência mental.

Os procedimentos de coleta de dados técnicos foram de caráter descritivo, apoiados nos pressupostos teórico-metodológicos da pesquisa de campo, com enfoque histórico-cultural. Desse modo, utilizaram-se os seguintes procedimentos metodológicos: a) pesquisa bibliográfica; b) pesquisa de campo através de questionário estruturado, com perguntas fechadas.

Ressalta-se que o universo de professores do ensino fundamental, ciclo II, integrantes da rede estadual de educação da regiāo de Marília-SP, é muito amplo, e um exame e/ou investigaçáo com todos os docentes que atendem a alunos com deficiência mental se mostrava inviável. Assim, dadas as questóes de tempo hábil para sua realização e natureza do trabalho em nível de especialização, optou-se por fazer uma pesquisa com amostragem desse universo, não necessariamente observando o quantitativo de professores $\mathrm{da}$ rede de ensino.

Assim, para a realização da pesquisa contou-se com a participação de dez professores, de diferentes turnos escolares de uma unidade escolar estadual do ensino fundamental, ciclo II, que corresponde a turmas do $6^{\circ}$ ao $9^{\circ}$ ano. A escola fica situada na zona urbana, num bairro da periferia da cidade de Garça, município integrante da Diretoria de Ensino da Região de Marília-SP, e funciona nos turnos diurno e noturno, atendendo uma demanda de alunos pertencentes a famílias de renda média baixa, classes $\mathrm{C}$ e D. Além de possuir turmas de $6^{\circ}$ ao $9^{\circ}$ ano, atende ao ensino médio e possui uma sala de atendimento a educação especial, na área de deficiência mental.

A escolha dos professores do ensino fundamental, ciclo II, para a realização da pesquisa, se deu não apenas por uma predileção pessoal do pesquisador por esta fase, mas pela percepção de que neste ciclo do ensino fundamental há uma diversificação de profissionais que lidam com a educação, como professores de português, matemática, ciências, história, entre outros, nem sempre formados para lidar com alunos com necessidades educativas especiais.

Observa-se que os docentes desta fase do ensino fundamental são capacitados para lidar principalmente com as matérias específicas de suas áreas e, muitas vezes, não têm a oportunidade de desenvolver uma formação na área da educação especial no currículo de graduação. Por isso, percebemse muitas queixas e dificuldades em lidar com a inclusão nesta fase. 
A angústia de muitos professores é grande, a ponto de se sentirem incapazes de administrar a situação. Somando-se à falta de formação especializada, preferem ignorar os alunos deficientes, ou náo colaborar com a inclusão por falta de conhecimento ou preparo adequado. Realidade esta confirmada também por Carvalho (2004, p. 113), ao afirmar: "muitos dos nossos professores do ensino fundamental alegam que não se sentem 'preparados' e motivados para a docência de grupos táo diversificados." Tal constatação permite deduzir e/ou chegar ao indício de que a escolha por fazer a pesquisa com os docentes do nível II do ensino fundamental pode ter sido acertada, necessária e útil para a ampliação das discussóes nesse campo.

Conforme já indicado, o método utilizado para a pesquisa de campo foi a aplicação de um questionário estruturado, com perguntas fechadas, realizado na semana entre os dias 22 e 25 de fevereiro de 2011, na própria unidade escolar indicada na pesquisa, em diferentes turnos escolares. A aplicação do questionário para a coleta de dados, realizado sem debate e/ ou intervenção do pesquisador, foi na sala dos professores da referida escola, durante o intervalo e no término das aulas.

O questionário elaborado constou de 8 (oito) perguntas sobre diferentes questões e/ou situaçóes ligadas à inclusão do aluno com deficiência mental na classe regular. Abordava também a percepção dos docentes sobre suas práticas pedagógicas inclusivas e suas reflexóes acerca das possibilidades e impossibilidades da inserçáo de alunos com deficiência mental na sala regular de ensino.

As perguntas elaboradas no questionário não foram concebidas de modo aleatório ou como resultado de preocupaçóes de foro íntimo do pesquisador; pelo contrário, refletem inquietaçôes teóricas constantemente evocadas nas literaturas e por pesquisadores da área da educação especial.

$\mathrm{Na}$ aplicação do questionário para a coleta de dados ressalta-se, ainda, que o pesquisador não constatou, entre os docentes investigados, grandes dificuldades na efetivação das respostas que mereçam destaque.

\section{Resultados}

Discutidos os aspectos metodológicos, apresentar-se-âo os resultados da pesquisa de campo junto aos professores do ciclo II do ensino fundamental, da unidade escolar referida, em relação a seus discursos sobre a inclusão dos alunos com deficiência mental (DM) em sala regular de ensino. 
A primeira questáo investigada pela pesquisa diz respeito à opiniáo dos professores sobre a importância de se promover a integração dos alunos "normais" com os alunos deficientes mentais/intelectuais, visando contribuir para a aceitação das diferenças. Os dados demonstram que $60 \%$ dos professores entendem ser importante promover a integração dos alunos "normais" com os deficientes no processo de aceitação das diferenças. Outra parte desses docentes, 30\%, acredita na integração de forma parcial. E 10\% dos docentes pesquisados se mostraram indiferentes a essa prática.

A segunda questáo que a pesquisa analisa junto aos docentes é se as necessidades dos estudantes com deficiência mental podem ser melhor atendidas em classes especiais. Neste caso, $60 \%$ dos professores indicaram que as necessidades dos estudantes com deficiência mental podem ser melhor atendidas em classes especiais. Outros 30\% desses docentes sinalizaram que são parcialmente favoráveis ao atendimento do DM em classe especial, e $10 \%$ revelaram ser indiferentes em relação ao atendimento do deficiente em classe especial.

A terceira questão consultava se as açóes pedagógicas realizadas em sala de aula com os estudantes "normais" são pensadas apropriadamente para facilitar o desempenho dos estudantes com DM. A pesquisa demonstrou que $50 \%$ dos professores apontam que há uma adequação parcial das ações pedagógicas. Já $30 \%$ se mostraram indiferentes. E 20\% dos professores se preocupam em adaptar as açóes pedagógicas realizadas em sala de aula para facilitar o desempenho dos estudantes com DM.

Em relação à quarta pergunta, foi feita investigação junto aos professores se a disciplina e a ordem na sala de aula regular são alteradas devido à presença dos DM. Observou-se que $60 \%$ dos professores salientam que a presença do DM em classe regular pode interferir parcialmente na ordem da classe. Enquanto 40\% dos professores entendem que a presença do aluno com deficiência mental não aumenta nem diminui os problemas de indisciplina na classe, ou seja, se mostram indiferentes.

$\mathrm{Na}$ quinta pergunta, foi examinado se a atenção extra que estudantes com DM requerem pode prejudicar os outros estudantes. Verificou-se que $60 \%$ dos professores se mostraram indiferentes quanto a possíveis prejuízos a alunos regulares devido à atenção extra que os DM requerem. E 30\% dos docentes entenderam que esses prejuízos ocorriam de forma parcial. Já $10 \%$ relataram que os estudantes com DM trazem prejuízo aos outros estudantes. 
Na sexta pergunta, foi investigado junto aos professores se o DM desenvolveria mais rapidamente sua capacidade de aprendizagem em uma classe especial do que em uma classe regular. Nessa pergunta, os dados demonstram que $50 \%$ dos professores indicam que a criança com DM desenvolveria mais rapidamente sua capacidade de aprendizagem em uma classe especial do que em uma classe regular. Já 30\% dos docentes se mostraram indiferentes e 20\% parcialmente a favor da classe especial para esses estudantes.

A sétima pergunta questionava sobre a importância de o professor da classe regular procurar ter preparação para ensinar as crianças com DM, no sentido de promover a inclusão. A opinião dos professores foi quase unânime: $90 \%$ concordaram com a necessidade de se ter preparaçáo para ensinar as crianças com DM; apenas 10\% se mostraram indiferentes.

E, por fim, a oitava pergunta investigou se a cooperação do professor é imprescindível para se promover uma inclusão de qualidade. Observou-se que $90 \%$ dos professores entendem que a sua influência é significativa na promoção de uma inclusão de qualidade. Realidade esta não defendida por $10 \%$ dos professores entrevistados. Esses dados são importantes indicativos de que a maioria dos professores se reconhece como agentes valiosos e determinantes para uma ação pedagógica inclusiva na escola.

\section{Discussáo}

Refletindo sobre os dados apresentados acima, no que tange aos discursos da classe professoral sobre a inclusão de crianças com deficiência mental (DM), é possível compreender vários aspectos valiosos em relação ao assunto, que oferecem subsídios importantes para a revitalização da prática pedagógica de educadores no campo da inclusão.

Primeiramente, observou-se que, apesar de o conceito de diversidade e inclusão fazer parte das políticas educacionais brasileiras já há algumas décadas, a pesquisa revela um distanciamento entre teoria e prática, leis e aplicaçôes pedagógicas no cotidiano escolar, pois é comum no discurso dos professores o relato de dificuldades na implementação da prática inclusiva na escola. Todavia, tal distanciamento se evidencia mais pela dificuldade de aceitação dos professores em lidar com a inclusão do que por falta de políticas públicas de inclusão e/ ou falta de capacitação oferecida pelo sistema educacional - já que, além de a Diretoria de Ensino oferecer capacitaçóes periódicas, nas reuniôes pedagógicas semanais das escolas a coordenação promove reflexóes e discussóes sobre o tema. 
Em segundo lugar, observou-se uma incoerência no discurso dos professores sobre a aceitação da inclusão, tendo em vista que, apesar de sinalizarem em vários momentos que são favoráveis a essa prática, indicam que os alunos com deficiência mental podem ser melhor atendidos em classes especiais. Essa aparente duplicidade no discurso dos professores pode ser indicativa de um preconceito velado ou uma não aceitação concreta da prática inclusiva. Também pode revelar conflitos internos e subjetivos que acompanham a prática docente: medo, insegurança, angústia, insatisfação, desmotivação, descaso.

Em terceiro lugar, notamos certo desinteresse dos professores em efetivar ações pedagógicas para uma prática inclusiva em relação ao DM. Isso se evidencia no relato da maioria dos docentes, de que nem sempre têm preocupação em adaptar pedagogicamente as atividades curriculares às necessidades do deficiente mental.

Um dos fatores determinantes para o sucesso da inclusáo escolar no Brasil deve ser a disposição para a mudança. A inclusão só ocorrerá de fato se os professores e os demais profissionais ou pessoas envolvidas estiverem dispostos a adequar suas práticas ao contexto da diversidade. É preciso reconhecer, contudo, que a mudança de atitude não se compra nem se impóe; é preciso haver conscientização e sensibilização para se transformar o desejo numa ação ativamente inclusiva e propícia, que possibilite o sucesso escolar dos alunos com necessidades educativas especiais.

A atuação do professor como facilitador do processo de inclusão na classe escolar comum se faz constantemente necessária. Quando ele possui clareza sobre esses aspectos assinalados acima consegue atender com qualidade a inclusão, e o aluno com deficiência pode tirar bom proveito do atendimento educacional adequado a suas necessidades.

O deficiente mental na sala de aula lança um grande e complexo desafio para pensarmos a inclusão escolar. Sabemos que caberáo ainda muitas mudanças e adaptaçôes na relação entre teoria e prática da educação inclusiva, mas o mais importante é que as discussões já estão acontecendo e novos caminhos estão sendo descobertos.

\section{Conclusóes}

O mundo atual não comporta mais uma prática educacional que segrega, estigmatiza, marginaliza e exclui pessoas com deficiência, apesar de 
se identificarem ainda algumas dessas condenáveis práticas sendo repetidas no interior de algumas escolas no Brasil. A escola deve se propor, nesses novos tempos, acolher a diversidade. Nesse processo, professores, gestores, agentes educacionais e a comunidade envolvida com a escola exercem um papel de grande relevância, como apoio e agentes de transformação.

Como foi visto, a inclusão escolar é uma proposta bastante complexa e que envolve inúmeros atores. O professor, pela sua proximidade aos alunos em sala de aula, é o grande protagonista que pode exercer um papel de grande impacto na vida destes, tanto positivo quanto negativo, em termos de uma inclusão ativa. Daí, razão desta pesquisa, analisar a prática docente e a aceitação da inclusão do deficiente intelectual na sala de aula regular do ensino fundamental. É visível a longa distância entre o ideal da lei e o real da prática, que se agrava com a falta de estrutura e adequação para atender aos princípios da diversidade.

Concluindo, temos a compreensão de que os resultados apresentados na pesquisa náo podem ser estendidos ao universo total de professores da Diretoria de Ensino da Região de Marília. Todavia, procurou-se através da pesquisa investigar, a partir de uma amostragem, como uma parcela dos professores do ensino fundamental, ciclo II, lidam com a inclusão do deficiente mental na sala comum ou regular de ensino. Pretende-se, a partir dessas investigaçóes, contribuir com o debate acadêmico sobre o tema, e auxiliar professores em suas lutas diárias para adequar suas práticas pedagógicas e metodológicas para lidar com a diversidade e a inclusão de alunos com deficiência mental.

\section{Referências}

ASSOCIAÇÃO PSIQUIÁTRICA AMERICANA. Manual diagnóstico e estatístico de transtornos mentais. 4. ed. Porto Alegre: ArtMed, 1994.

BRASIL. Ministério da Educação. Lei de Diretrizes e Bases da Educação NacionallLDB n. 9.394, de 20 de dezembro de 1996.

BRASIL. Ministério da Educação. Secretaria de Educação Fundamental. Declaração Mundial sobre Educação para Todos: satisfação das necessidades básicas de aprendizagem. In: Plano Decenal de Educação para Todos. Brasília: MEC/SEF, 1993. 
BRASIL. Declaração dos Direitos das Pessoas Deficientes, 1975. Brasília, MEC. Disponível em: <http://portal.mec.gov.br/seesp/arquivos/pdf/dec_ def.pdf $>$. Acesso em: 26 fev.2011.

BRASIL. Saberes e práticas da inclusão: recomendaçôes para a construção de escolas inclusivas. 2. ed. Coordenação Geral, SEESP/MEC. Brasília: Secretaria de Educação Especial, 2006.

CARVALHO, R. E. Educação Inclusiva: com os pingos nos "is". Porto Alegre: Mediação, 2004.

DECLARAÇÃO de Salamanca e linha de ação sobre necessidades educativas especiais. Brasília: CORDE, 1994.

DSM-IV. Manual diagnóstico e estatístico de transtornos mentais. Porto Alegre: Artes Médicas, 1995.

KASSAR, M. C. G. Matrículas de crianças com necessidades educacionais especiais na rede de ensino regular. In: LAPLANE, A. L. F.; GÓES, M. C. R. (Org.). Politicas e práticas de educação inclusiva. Campinas-SP: Autores Associados, 2004. p. 49-67.

MAZZOTTA, M. J. S. Educação escolar: comum ou especial. São Paulo: Pioneira, 1987.

ORGANIZAÇÃO MUNDIAL DE SAÚDE. Classificação de transtornos mentais e de comportamento da CID-10. Porto Alegre: Artes Médicas, 1993.

PLETSCH, M. D. Repensando a inclusão escolar: diretrizes políticas, práticas curriculares e deficiência intelectual. 1. ed. Rio de Janeiro: NAU/EDUR, 2010 .

SASSAKI, R. K. Inclusão: construindo uma sociedade para todos. 3. ed. Rio de Janeiro: WVA, 1999.

UNESCO. Declaração Mundial sobre Educação para Todos: satisfação das necessidades básicas de aprendizagem. Conferência Mundial sobre Educação para Todos. Jomtiem, Tailândia, 5 a 9 mar. 1990. Peru, 2001.

Recebido em: 31 jul. 2012

Aceito em: 14 set. 2012 
